\title{
MORFOLOGIA DE FRUTO, SEMENTE E PLÂNTULA, E GERMINAÇÃO DE SEMENTES DE Myrceugenia euosma (O. BERG) D. LEGRAND (MYRTACEAE)
}

\author{
Nelson Luiz Cosmo ${ }^{1}$, Alessandra Mara Gogosz ${ }^{1}$, Suelen Santos Rego ${ }^{2}$, Antonio Carlos Nogueira ${ }^{3}$, \\ Yoshiko Saito Kuniyoshi ${ }^{3}$ \\ ${ }^{1}$ Faculdades Integradas Espírita, Curitiba, Paraná, Brasil - ncosmo@gmail.com,; alegogosz@gmail.com \\ ${ }^{2}$ União Latino-Americana de Ensino, Jaguariaíva, Paraná, Brasil - sureggae@yahoo.com.br \\ ${ }^{3}$ Universidade Federal do Paraná, Curitiba, Paraná, Brasil - nogueira@ufpr.br ${ }^{3}$ - yoshiko@ufpr.br ${ }^{3}$ \\ Recebido para publicação: 02/06/2016 - Aceito para publicação 19/10/2017
}

\begin{abstract}
Resumo
Myrceugenia euosma (O. Berg) D. Legrand (Myrtaceae) tem porte arbóreo ou arbustivo, com ocorrência na América do Sul, principalmente no Chile e no sul do Brasil. Objetivou-se estudar a morfologia de fruto, semente e plântula, e a germinação de sementes desta espécie. Os frutos foram coletados de cinco matrizes em remanescente de Floresta Ombrófila Mista Aluvial em Araucária - PR. Foi testada a influência de diferentes substratos (papel, rolo de papel e areia), temperaturas $\left(20^{\circ} \mathrm{C}, 25^{\circ} \mathrm{C}\right.$ e $\left.30^{\circ} \mathrm{C}\right)$ e condições de luz (presença e ausência) sobre a germinação das sementes. M. euosma tem fruto do tipo baga, contendo de 2 a 13 sementes, envolvidas por tegumento membranáceo, com endosperma mucilaginoso, evidente apenas na germinação. O embrião é mircióide, típico da subtribo Myrciinae, e a plântula é epígea, fanerocotiledonar. A germinação tem início entre três e cinco dias e, com exceção do substrato rolo de papel na temperatura $30^{\circ} \mathrm{C}$, os demais tratamentos apresentaram percentuais relativamente altos de germinação $(\approx 72 \%)$. As sementes são fotoblásticas neutras. Os resultados indicam que M. euosma tem poucas restrições em termos reprodutivos quanto à germinação.
\end{abstract}

Palavras-chave: Myrciinae; Floresta Ombrófila Mista; Floresta com Araucária.

\begin{abstract}
Morphology of fruit, seed and seedling and seed germination of Myrceugenia euosma (O. Berg) D. Legrand (Myrtaceae). Myrceugenia euosma is a tree or shruby species that occurs in South America in two major centers: Chile and south of Brazil. The objective of this work was to study the morphology of the fruit, seed and seedling and the seed germination of this species. Fruit, seed and seedling were illustrated and described. The influence of three substrates (paper towels, paper roll and sand), temperatures $\left(20^{\circ} \mathrm{C}, 25^{\circ} \mathrm{C}\right.$ and $30{ }^{\circ} \mathrm{C}$ ) and conditions of light (presence and absence) over the seed germination were evaluated. The fruit of $M$. euosma is a berry, containing 2 to 13 seeds. The seed has membranaceous tegument, small amount of mucilaginous endosperm, evident only in germination, and embryo typical of the subtribe Myrciinae. The seedling is epigea, phanerocotylar, with paracotyledons and eophylls simple, opposites. Germination started three to five days after the test installation. Almost all treatments resulted in relatively high germination percentage $(\approx 72 \%)$, except in paper roll at $30^{\circ} \mathrm{C}(43 \%)$. The species germinates in the absence of light. The results indicate that $M$. еuosma has few reproductive restrictions with regard to germination.

Keywords: Myrciinae, Mixed Ombrophylous Forest, Araucaria forest.
\end{abstract}

\section{INTRODUÇÃO}

Myrtaceae é uma das famílias mais representativas da flora brasileira, com 23 gêneros e aproximadamente 1.000 espécies nativas (SOUZA; LORENZI, 2005). Na região sul do Brasil, ocorre, principalmente, na Floresta Ombrófila Mista, correspondendo ao maior número de espécies arbóreas dessa formação (BARBIERI; HEIDEN, 2009). Além de sua representatividade em termos de número de espécies, a família apresenta relevância ecológica pelas características dos frutos, uma vez que estes são considerados importante fonte de alimentos para a fauna silvestre (GRESSLER et al., 2006). Trata-se de uma família botânica indicada para restauração de áreas alteradas, enriquecimento de florestas secundárias e usos ornamentais e fitoterápicos (GOMES et al., 2017).

O gênero Myrceugenia compreende espécies arbóreas e arbustivas distribuídas na América do Sul em dois centros principais: no Chile e no sul do Brasil (LEGRAND; KLEIN, 1970). Está presente, também, no Uruguai (GAUTREAU; LEZAMA, 2009), Argentina e Paraguai (LANDRUM, 1981). Myrceugenia euosma (O.

FLORESTA, Curitiba, PR, v. 47, n. 4, p. 479 - 488, out. / dez. 2017.

Cosmo; N,L, et al.

ISSN eletrônico 1982-4688

479

DOI: $10.5380 /$ rf.v47i4.46933 
Berg) D. Legrand ocorre como arbusto ou arvoreta, com tronco geralmente tortuoso e casca espessa, escura, com fissuras longitudinais. Os ramos jovens, pecíolos e pedúnculos possuem indumento seríceo denso, amareloocráceo e as flores são solitárias ou dispostas em pares na extremidade de pedúnculos curtos, com $5 \mathrm{a} 15 \mathrm{~mm}$, axilares (MARCHIORI; SOBRAL, 1997). A espécie tem dispersão zoocórica, com floração e frutificação variando de setembro a fevereiro e de julho a novembro, respectivamente (CARMO; MORELLATO, 2000; GOMES et al., 2017).

Trata-se de espécie seletiva higrófila, segundo Legrand e Klein (1970), por ser frequentemente encontrada em solos bastante úmidos, eventualmente sujeitos à saturação hídrica, tais como os que condicionam a ocorrência da Floresta Ombrófila Mista Aluvial, onde a espécie é frequente como árvore do estrato inferior (CARMO; MORELLATO, 2000).

Nota-se que $M$. euosma tem considerável plasticidade, uma vez que ocorre nas diferentes formações da Floresta Ombrófila Mista: Montana (VALÉRIO et al., 2008), Altomontana (SILVA et al., 2017) e Aluvial (CARMO; MORELLATO, 2000). Também ocorre na formação Altomontana da Floresta Ombrófila Densa (LEGRAND; KLEIN, 1970). As variações morfológicas observadas na espécie entre as diferentes procedências motivaram sua divisão, por Legrand e Klein (1970), em cinco grupos distintos, baseando-se nas características das folhas principalmente.

Alguns estudos fazem referência a aspectos bioquímicos da espécie, como a presença de óleos essenciais (LIMBERGER, 2002) e do Ácido Morônico que, isolado de M. euosma, mostra significativa atividade anti-HIV (SINGH et al., 2005).. Apesar disso, M. euosma é pouco conhecida em sua área de ocorrência natural e há carência de estudos sobre as variações morfológicas e ecofisiológicas da espécie.

$\mathrm{O}$ estudo das características morfológicas associadas à ecologia das espécies nativas possibilita um melhor entendimento da funcionalidade dessas estruturas nos ecossistemas, contribuindo para o desenvolvimento de programas de conservação e restauração ambiental. Dentre os estudos que tratam desse tema, destacam-se: Gogosz et al. (2015); Gomes et al. (2017); Silva et al. (2017); e Valério et al. (2008). No caso da espécie estudada, seus usos potenciais e sua ocorrência como uma das espécies dominantes em comunidades da Floresta Ombrófila Mista (VALÉRIO et al., 2008; SILVA et al., 2017), a tornam ainda mais relevante em programas de restauração que visem o reestabelecimento dos serviços ecossistêmicos.

A germinação representa uma fase crítica do ciclo de vida das espécies vegetais e os fatores que a afetam, tais como temperatura, tipo de substrato, umidade e luminosidade, são relevantes tanto em termos tecnológicos quanto ecológicos. Tais fatores interferem diretamente na porcentagem de sementes germinadas e na velocidade com que este processo ocorre. Portanto, a análise da germinação de sementes é base para a propagação de espécies nativas e para o entendimento da regeneração natural em comunidades vegetais. Alguns autores têm estudado aspectos tecnológicos e/ou ecomorfológicos do processo germinativo em espécies nativas de Myrtaceae: Gogosz et al. (2010, 2015), Gomes et al. (2016), Rego et al. (2009, 2010, 2011), e Santos et al. (2015).

Desta forma, objetivou-se analisar e ilustrar os caracteres morfológicos de frutos, semente e plântula de Myrceugenia. euosma, além de avaliar a influência de diferentes substratos, temperaturas e condições de luz sobre a germinação das sementes.

\section{MATERIAL E MÉTODOS}

\section{Coleta e beneficiamento dos frutos e sementes}

Os frutos de Myrceugenia euosma foram coletados de cinco matrizes no mês de novembro de 2008 na Floresta Ombrófila Mista Aluvial na planície do rio Verde, próximo à sua confluência com o rio Iguaçu, em Araucária - PR. A extração das sementes foi realizada manualmente pela maceração e a lavagem dos frutos foi feita em água corrente. Em seguida, as sementes foram deixadas para secar em ambiente aberto por 24 horas.

\section{Morfologia e biometria do fruto e da semente}

Para a ilustração e descrição morfológica do fruto e da semente, foram tomadas 100 unidades aleatórias. As observações foram feitas com estereomicroscópio e a olho nu. Foram mensurados os frutos (comprimento e diâmetro) e as sementes (comprimento e largura), utilizando paquímetro digital. Também foi obtido o peso de mil sementes e o número de sementes por quilo, conforme as regras de análise de sementes (BRASIL, 2009), bem como o número de sementes por fruto.

\section{Morfologia da plântula}

Para a observação do desenvolvimento da plântula, foram colocadas 100 sementes para germinar em bandejas plásticas, com substrato constituído de casca de pinus e vermiculita. As fases de desenvolvimento e as características morfológicas relevantes foram ilustradas e descritas de acordo com a nomenclatura proposta por 
Vogel (1980). Tal nomenclatura também foi utilizada para classificar a plântula, segundo a forma de germinação, expansão e desenvolvimento dos paracotilédones e do hipocótilo. A morfologia dos paracotilédones e dos eofilos foi descrita segundo Hickey (1979). O período de avaliação correspondeu ao intervalo entre o início da expansão do hipocótilo e a total expansão do primeiro par de eofilos.

\section{Teste de germinação}

Foram testados três substratos: papel, rolo de papel e areia, em três temperaturas: $20{ }^{\circ} \mathrm{C}, 25^{\circ} \mathrm{C}$ e $30^{\circ} \mathrm{C}$. Em um segundo teste, foi avaliado o efeito da presença e da ausência de luz sobre a germinação. Em ambos os testes, cada tratamento foi constituído de cinco repetições com 40 sementes cada. Todos os substratos foram esterilizados em estufa regulada a $105^{\circ} \mathrm{C} \pm 3^{\circ} \mathrm{C}$ durante 24 horas. Para o substrato papel, foram colocadas quatro camadas de folhas de papel tipo germitest no fundo de caixas de plástico (gerbox), acrescentando-se água destilada, o suficiente para umedecer completamente as folhas e o excesso de água sendo retirado por gravidade. Em cada gerbox, foram colocados $100 \mathrm{~g}$ de areia esterilizada e $25 \mathrm{ml}$ de água destilada. No substrato rolo de papel, as sementes foram postas entre dois pares de folhas de papel germitest, umedecidos com água destilada e posteriormente enrolados. $\mathrm{O}$ experimento foi montado em germinadores tipo Biomatic regulados em $20{ }^{\circ} \mathrm{C}, 25$ ${ }^{\circ} \mathrm{C}$ e $30^{\circ} \mathrm{C}$.

Foram utilizados gerbox transparentes para o tratamento com luz e gerbox pintados com tinta acrílica preta para a germinação na ausência de luz. Em ambos, as sementes foram colocadas sobre quatro folhas de papel, umedecidas com água destilada. O experimento foi montado em germinador do tipo Biomatic em temperatura de $25^{\circ} \mathrm{C}$. As amostras foram analisadas em câmara escura, sob lâmpada recoberta com filtro verde, com comprimento de onda entre 490 e $560 \mathrm{~nm}$.

\section{Análise de dados}

As avaliações foram realizadas diariamente até que, praticamente, não ocorresse mais germinação. Como critério para sementes germinadas, considerou-se a emissão de radícula com mais de $2 \mathrm{~mm}$.

Foram avaliados: o percentual final de germinação (PG), o tempo médio (TM) e o índice de velocidade de germinação (IVG), obtidos da seguinte forma:

em que:

$$
\begin{gathered}
\mathrm{IVG}=\mathrm{G} 1 / \mathrm{N} 1+\mathrm{G} 2 / \mathrm{N} 2+\ldots \mathrm{Gn} / \mathrm{Nn} ; \\
\mathrm{TM}=\sum \text { ni } . \mathrm{ti} / \sum \mathrm{ni}
\end{gathered}
$$

G1, G2, Gn = número de sementes contadas na primeira, na segunda e na enésima contagem, respectivamente;

$\mathrm{N} 1, \mathrm{~N} 2, \mathrm{Nn}=$ número de dias decorridos até a primeira, a segunda e a enésima contagem;

ni $=$ número de sementes germinadas no dia $\mathrm{i}$;

ti = número de dias decorridos após a instalação do teste.

Foi utilizado um delineamento inteiramente casualizado. A influência da temperatura e do substrato foi avaliada em esquema fatorial 3x3 (3 temperaturas x 3 substratos) e o experimento com diferentes condições de luz foi constituído de dois tratamentos (com luz e sem luz). Os dados obtidos para substrato e temperatura foram submetidos ao teste de Bartlett e à análise de variância, e as médias comparadas pelo teste de Tukey a 5\% de probabilidade. Para a comparação entre as médias de germinação com e sem luz, foi aplicado o teste " $t$ " e considerada a probabilidade de $5 \%$.

\section{RESULTADOS}

\section{Morfologia do fruto, da semente e da plântula}

O Fruto de Myrceugenia euosma é do tipo baga (Figura 1), subgloboso a piriforme, com exocarpo piloso, verde quando imaturo a roxo-escuro quando maduro. $\mathrm{O}$ mesocarpo é carnoso, com poupa pouco abundante e de coloração alaranjada. Os frutos têm 5,7 $\mathrm{mm}$ de comprimento e 5,3 $\mathrm{mm}$ de diâmetro transversal, contendo em média 5 sementes, variando de 2 a 13 (Tabela 1). A semente contém pequena quantidade de endosperma mucilaginoso (evidente apenas após a germinação) e é envolta por tegumento membranáceo, translúcido, com hilo e micrópila diminutos. As sementes têm, em média, 3,5 mm de comprimento, 2,8 $\mathrm{mm}$ de largura e pesam em média $9,96 \mathrm{mg}$ cada.

Tabela 1. Características físicas de frutos e sementes de Myrceugenia euosma (O. Berg) D. Legrand (Myrtaceae). 
Table 1. Physical characteristics of fruits and seeds of Myrceugenia euosma (O. Berg) D. Legrand (Myrtaceae).

\begin{tabular}{llcccc}
\hline & & Mínimo & Média $\pm \mathrm{s}$ & Máximo & CV (\%) \\
\hline \multirow{4}{*}{ Frutos } & comprimento (mm) & 4,1 & $5,7 \pm 0,8$ & 7,6 & 13,9 \\
& diâmetro (mm) & 4,0 & $5,3 \pm 0,7$ & 7,3 & 13,2 \\
& $\mathrm{n}^{\text {o de sementes }}$ & 2,0 & $5,1 \pm 2,2$ & 13,0 & 43,5 \\
\hline \multirow{5}{*}{ sementes } & comprimento (mm) & 2,3 & $3,5 \pm 0,5$ & 4,9 & 14,9 \\
& largura (mm) & 1,7 & $2,8 \pm 0,4$ & 3,9 & 16,1 \\
& peso de 1000 (g) & 9,40 & $9,96 \pm 0,06$ & 10,70 & 5,9 \\
& $\mathrm{n} / \mathrm{Kg}$ & - & $100.376,41$ & - & - \\
\hline
\end{tabular}

s: desvio padrão; CV (\%) Coeficiente de variação.

O embrião de M. euosma é conduplicado, típico da subtribo Myrciinae (embrião do tipo mircióide), com hipocótilo relativamente longo, curvo, verde escuro e paracotilódones bastante dobrados. O hipocótilo tem a epiderme densa com glândulas visíveis à lupa, provavelmente contendo óleos essenciais.
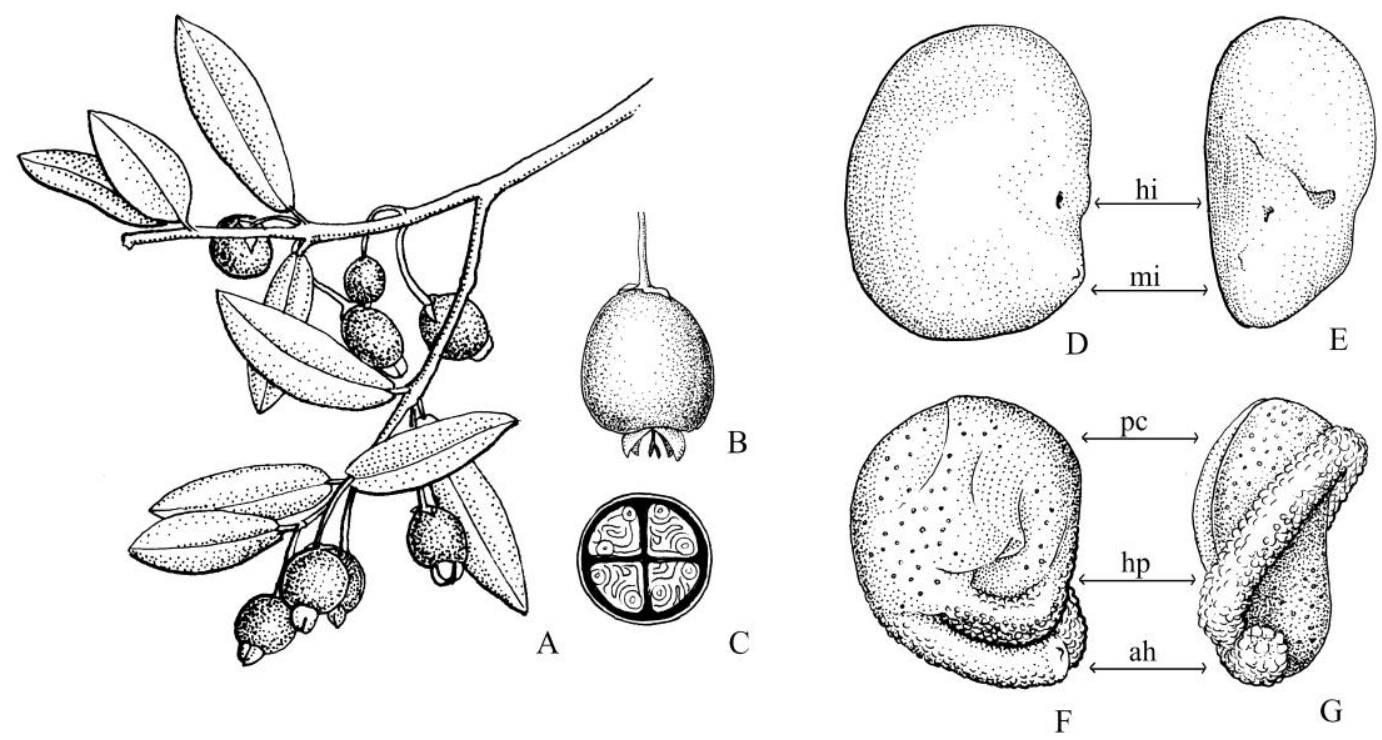

Figura 1. Morfologia do fruto e da semente de Myrceugenia euosma (O. Berg) D. Legrand (Myrtaceae). A: ramo com frutos; B: aspecto externo do fruto; C: corte transversal do fruto; D-E: aspecto externo da semente; F-G: morfologia do embrião; ah: ápice do hipocótilo; hi: região do hilo; mi: região da micrópila. (Ilustração: Como, N. L.)

Figure 1. Morphology of the fruit and seed of Myrceugenia euosma (O. Berg) D. Legrand (Myrtaceae). A: branch with fruit; B: external aspect of the fruit; C: cross-section of fruit; D-E: External seed aspect; F-G: Embryo morphology; ah: hypocotyl apex; hi: hilar region; mi: the micropyle region. (Illustration: Como, N. L.)

O início do desenvolvimento da plântula (Figura 2) se dá com o rompimento do tegumento na região micropilar e expansão do hipocótilo. A protrusão da raiz primária só ocorre alguns dias após a emissão do hipocótilo e a formação de pelos na extremidade deste.

Após o alongamento inicial do hipocótilo e a emissão da raiz primária, ocorre a liberação dos paracotilédones, que permanecem dobrados enquanto o hipocótilo se eleva. Depois que os paracotilédones estão completamente expandidos, ocorre a emissão do primeiro par de eofilos, que permanecem unidos enquanto a lâmina foliar se expande, abrindo-se em seguida. A plântula tem, portanto, desenvolvimento epígeo, fanerocotiledonar. 

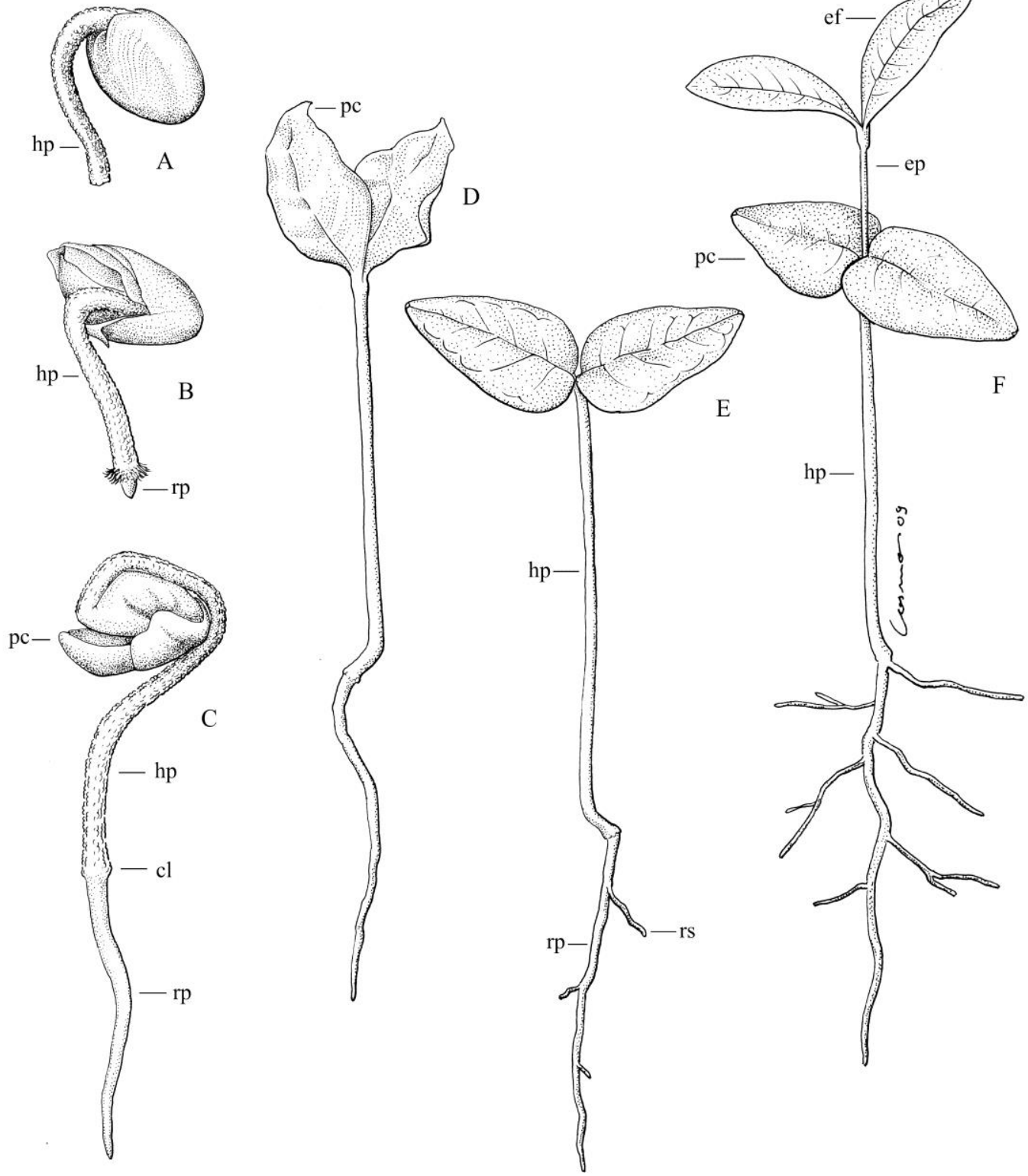

Figura 2. Desenvolvimento da plântula de Myrceugenia euosma (O. Berg) D. Legrand (Myrtaceae). A: expansão inicial do hipocótilo; B: protrusão da raiz primária; C: crescimento do hipocótilo e da raiz; D-E: abertura e expansão dos paracotilédones; F: plântula com eofilo expandido; cl: colo; ef: eofilo; ep: epicótilo; hp: hipocótilo; pc: paracotilédone; rp: raiz primária; rs: raiz secundária. (Ilustração: Como, N. L.)

Figure 2. Seedling development of Myrceugenia euosma (O. Berg) D. Legrand (Myrtaceae). A: initial expansion of the hypocotyl; B: primary root protrusion; C: growth of hypocotyl and root; D-E: opening and expansion of paracotyledons; F: seedling with expanded eophyll; cl: colo; f: eophyll; p: epicotyl; hp: hypocotyl; pc: paracotyledon; rp: primary root; rs: secondary root. (Illustration: Como, N. L.)

Tanto os paracotilédones quanto os eofilos de $M$. euosma são curto-peciolados, glabros, com margem inteira, levemente discolores. Em ambos, a venação é pouco evidente, com um padrão broquidódromo, considerando a nomenclatura de Hickey (1979), no qual as nervuras secundárias unem-se próximo à margem da lâmina em uma série de arcos.

FLOREST A, Curitiba, PR, v. 47, n. 4, p. 479 - 488, out. / dez. 2017.

Cosmo; N,L, et al.

ISSN eletrônico 1982-4688

DOI: $10.5380 /$ rf.v47i4.46933 
Os paracotilédones têm cor verde escura, forma ovada, com cerca de 12x10 mm, base e ápice arredondados, apresentando uma glândula diminuta no ápice da nervura central. O eofilo tem forma elíptica, com $15 \times 05 \mathrm{~mm}$, com base e ápice agudos. Sua coloração é nitidamente mais clara que a do paracotilédone.

Exceto pelo fato de não apresentar tricomas, o eofilo é bastante semelhante à folha típica da planta adulta (metafilo), considerando a descrição desta por Legrand e Klein (1970) e Marchiori e Sobral (1997) e o material botânico coletado das matrizes utilizadas neste estudo. Além disso, o padrão de venação do tipo broquidódromo do eofilo e do paracotilédone coincide com o padrão do metafilo da espécie.

Eventualmente, foram observadas algumas plântulas com três paracotilédones e outras com dois hipocótilos, unidos próximos à região do colo ou ao longo de quase toda a sua extensão, porém estas representaram uma porcentagem pequena $(\approx 3 \%)$, em relação ao total de plântulas avaliadas para a descrição morfológica.

\section{Germinação}

A germinação das sementes de $M$. euosma iniciou-se de três a cinco dias após a instalação do teste. Ocorreu interação entre os tratamentos testados, porém pouca variação nos índices de germinação (PG, IVG, TM) entre os tratamentos, considerando a sobreposição entre as médias de vários tratamentos, observada análise estatística (Tabela 2). Em geral, a espécie apresentou valores relativamente altos de porcentagem de germinação (66\% a $83 \%$ ) e velocidade de germinação (2,5 a 3,2), com exceção da combinação de rolo de papel com temperatura de $30{ }^{\circ} \mathrm{C}\left(\mathrm{RP} \times 30^{\circ} \mathrm{C}\right)$, com apenas $43 \%$ de germinação e $\mathrm{IVG}=1,5$ (Tabelas 2 e 3 ).

Tabela 2. Porcentagem de germinação de sementes de Myrceugenia euosma (O. Berg) D. Legrand (Myrtaceae) em diferentes substratos e temperaturas.

Table 2. Percentage of seed germination of Myrceugenia euosma (O. Berg) D. Legrand (Myrtaceae) in different substrates and temperatures.

\begin{tabular}{lccc}
\hline & Temperaturas & $30^{\circ} \mathrm{C}$ \\
\hline Substratos & $20^{\circ} \mathrm{C}$ & $25^{\circ} \mathrm{C}$ & $66 \mathrm{ab}$ \\
\hline Papel & $82 \mathrm{a}$ & $83 \mathrm{a}$ & $43 \mathrm{~b}$ \\
Rolo de papel & $83 \mathrm{a}$ & $66 \mathrm{ab}$ & $76 \mathrm{a}$ \\
Areia & $75 \mathrm{a}$ & $75 \mathrm{a}$ & \\
\hline
\end{tabular}

Médias seguidas pela mesma letra não diferem entre si pelo teste de Tukey a $5 \%$ de probabilidade.

Means followed by the same letter do not differ by $t$ test at $5 \%$ probability.

Tabela 3. Índice de velocidade de germinação (IVG) de sementes de Myrceugenia euosma (O. Berg) D. Legrand (Myrtaceae) em diferentes substratos e temperaturas.

Table 3. Germination speed index (GSI) of Myrceugenia euosma (O. Berg) D. Legrand (Myrtaceae) seeds in different substrates and temperatures.

\begin{tabular}{cccc}
\hline & \multicolumn{3}{c}{ Temperaturas } \\
\hline Substratos & $20{ }^{\circ} \mathrm{C}$ & $25^{\circ} \mathrm{C}$ & $30^{\circ} \mathrm{C}$ \\
\hline Papel & $3,15 \mathrm{a}$ & $2,53 \mathrm{a}$ & $2,72 \mathrm{a}$ \\
Rolo de papel & $2,97 \mathrm{a}$ & $2,70 \mathrm{a}$ & $1,53 \mathrm{~b}$ \\
Areia & $2,57 \mathrm{ab}$ & $2,89 \mathrm{a}$ & $3,17 \mathrm{a}$ \\
\hline
\end{tabular}

Médias seguidas pela mesma letra não diferem entre si pelo teste de Tukey a 5\% de probabilidade.

Means followed by the same letter do not differ by $t$ test at $5 \%$ probability.

A partir da observação do tratamento em que ocorreram menor porcentagem e velocidade de germinação (RP x $30^{\circ} \mathrm{C}$ ) e maior tempo médio (Tabela 4), notou-se, em diversas plântulas, a ocorrência da expansão do hipocótilo e, até mesmo, a abertura dos paracotilédones, sem que tivesse havido desenvolvimento da raiz primária. $\mathrm{O}$ mesmo foi observado em outras combinações de tratamentos, especialmente na temperatura de $30^{\circ} \mathrm{C}$, o que pode indicar algum efeito inibidor da temperatura sobre o desenvolvimento da raiz.

Tabela 4. Tempo médio de germinação (TM) de sementes de Myrceugenia euosma (O. Berg) D. Legrand (Myrtaceae), em diferentes substratos e temperaturas.

Table 4. Average germination time (AT) of Myrceugenia euosma (O. Berg) D. Legrand (Myrtaceae) seeds in different substrates and temperatures.

\begin{tabular}{lccc}
\hline & \multicolumn{3}{c}{ Temperaturas } \\
\hline Substratos & $20^{\circ} \mathrm{C}$ & $25^{\circ} \mathrm{C}$ & $30^{\circ} \mathrm{C}$ \\
\hline Papel & $11,83 \mathrm{abc}$ & $10,91 \mathrm{c}$ & $11,18 \mathrm{bc}$
\end{tabular}


$\begin{array}{llll}\text { Rolo de papel } & 12,08 \mathrm{abc} & 10,91 \mathrm{c} & 12,87 \mathrm{ab}\end{array}$

Areia 13,31 a $11,97 \mathrm{abc} \quad 11,19 \mathrm{bc}$

Médias seguidas pela mesma letra não diferem entre si pelo teste de Tukey a $5 \%$ de probabilidade.

Means followed by the same letter do not differ by t test at $5 \%$ probability.

Quanto à resposta da espécie na presença ou ausência de luz durante a germinação, não houve diferenças estatísticas em nenhum dos índices analisados para M. euosma entre os dois tratamentos (Tabela 5), indicando que a espécie é indiferente a este fator.

Tabela 5. Porcentagem (PG), índice de velocidade (IVG) e tempo médio (TM) de germinação de sementes de Myrceugenia euosma (O. Berg) D. Legrand (Myrtaceae) na presença e na ausência de luz.

Table 5. Percentage (PG), speed index (GSI) and average germination time (TM) of Myrceugenia euosma (O. Berg) D. Legrand (Myrtaceae) seeds in the presence and absence of light.

\begin{tabular}{lllll}
\hline & & PG & IVG & TM \\
\hline \multirow{3}{*}{ Com luz } & Média & $66,50 \mathrm{a}$ & $2,76 \mathrm{a}$ & $11,20 \mathrm{a}$ \\
& Desvio & 11,80 & 0,45 & 1,75 \\
& CV & 17,74 & 16,30 & 15,63 \\
\hline \multirow{3}{*}{ Sem luz } & Média & $59,00 \mathrm{a}$ & $2,53 \mathrm{a}$ & $10,82 \mathrm{a}$ \\
& Desvio & 6,52 & 0,27 & 0,87 \\
& CV & 11,05 & 10,67 & 8,04 \\
\hline
\end{tabular}

Médias seguidas pela mesma letra não diferem entre si pelo teste de Tukey, a 5\% de probabilidade.

Means followed by the same letter do not differ by $t$ test at $5 \%$ probability.

\section{DISCUSSÃO}

A descrição morfológica realizada pode ser utilizada para a identificação de Myrceugenia euosma, embora estudos comparativos sejam necessários para determinar quais caracteres são mais importantes para diferenciá-la de outras espécies do mesmo gênero. De acordo com Landrum (1981), existem poucas referências sobre os frutos de Myrceugenia spp. e sobre sua variação intraespecífica, devido ao fato da maturação ocorrer, geralmente, nos meses de inverno (junho a setembro), quando poucas coletas são feitas. Além disso, esses não são bem conservados em exsicatas e são frequentemente atacados por insetos e fungos.

M. euosma possui várias características típicas da família, tais como a presença de glândulas secretoras, comum em vários órgãos de Myrtaceae (METCALFE; CHALK, 1950), o padrão broquidódromo de venação e a forma do embrião (mircióide), caraterística da subtribo Myrciinae.

A morfologia do embrião em Myrtaceae tem grande relevância para a taxonomia da família, pois é a partir dela que são definidas as três subtribos: Myrciinae, com embrião mircióide, conduplicado; Eugeniinae, com embrião eugenóide, com hipocótilo curto e cotilédones de reserva; e Myrtinae, com embrião pimentóide, com hipocótilo longo, curvado ou espiralado e cotilédones diminutos (LANDRUM, 1981). Espécies de Myrceugenia podem ser, portanto, distinguidas de todos os outros gêneros da tribo Myrteae pelo embrião mircióide, exceto dos gêneros da subtribo Myrciinae, para os quais algumas características das flores devem ser usadas na identificação (LANDRUM, 1981).

O tipo de embrião reflete-se na morfologia da plântula. Embriões do tipo mircióide dão origem a plântulas com desenvolvimento epígeo, fanerocotiledonar, com cotilédones foliáceos fotossintetizantes (paracotilédones), como na espécie estudada. Essas características permitem o rápido estabelecimento da plântula após a germinação, ocorrendo produção fotossintética dos cotilédones e eofilos logo no início do desenvolvimento, de modo a compensar a pequena quantidade de reservas do embrião. Tal estratégia é típica de espécies de rápido crescimento e heliófilas (GOGOSZ et al., 2015), como é o caso de M. euosma, segundo Legrand e Klein (1970).

Na maioria das espécies com cotilédones foliáceos, estes se expandem apenas após a germinação, como ocorre na subtribo Myrtinae em espécies como Blepharocalyx salicifolius (H.B.K.) Berg. (REGO et al., 2009), Campomanesia xanthocarpa O. Berg. (GOGOSZ et al., 2010), Curitiba prismatica (D. Legrand) Salywon \& Landrum. (REGO et al., 2011), Psidium cattleianum Sabine e Acca sellowiana (O. Berg) Burret. (GOMES et al., 2015). Em M. euosma, no entanto, quando as sementes são dispersas, a formação dos cotilédones está em fase bastante adiantada, bem como a do hipocótilo. Isso provavelmente representa vantagens adicionais no estabelecimento da espécie, em termos de resistência a fatores restritivos do meio (competição, predação, limitações edáficas, etc). Tal padrão pode ser evidência de algum tipo de viviparidade na espécie, que poderia ser

FLOREST A, Curitiba, PR, v. 47, n. 4, p. 479 - 488, out. / dez. 2017.

Cosmo; N,L, et al.

ISSN eletrônico 1982-4688

DOI: $10.5380 /$ rf.v47i4.46933 
elucidada a partir de estudos mais aprofundados, especialmente de aspectos ecofisiológicos, da maturação da semente e do desenvolvimento do embrião.

Outra característica peculiar é que, embora o padrão normal de desenvolvimento inicial da maioria das espécies seja a protrusão da raiz seguida pela expansão do hipocótilo, em M. euosma, ocorre o contrário. A protrusão da raiz primária ocorre alguns dias após a emissão do hipocótilo e ocorre a formação de pêlos radiculares na extremidade deste, padrão semelhante ao que ocorre em $C$. prismatica (REGO et al., 2011) e Myrceugenia gertii Landrum (REGO et al., 2010)

Quanto à germinação, nota-se que o processo é relativamente rápido em M. euosma $(\mathrm{TM} \approx 12$ dias) quando comparado ao das espécies de Myrtaceae analisadas por Santos et al. (2004), em que, com exceção de $C$. xanthocarpa $(\mathrm{TM} \approx 12$ dias), o tempo médio variou de 18 a 38 dias.

Altas porcentagens de germinação parecem ser comuns em Myrtaceae. Gogosz et al. (2010) observaram altos valores de germinação $(\approx 90 \%)$ em $C$. xanthocarpa, com valores de velocidade $(\mathrm{IVG} \approx 2,5)$ próximos aos aqui destacados para $M$. euosma (IVG $\approx 2,7$ ). GOMES et al. (2016) estudaram a germinação de Eugenia involucrata D. C., C. xanthocarpa, A. sellowiana e Eugenia pyriformis Cambess., com obtenção de altos percentuais de germinação em alguns dos tratamentos testados.

Santos et al. (2004) também observaram valores altos de germinação (>75\%) em A. sellowiana, Campomanesia xanthocarpa, Myrcianthes pungens e P. cattleyanum, em temperaturas de $15^{\circ} \mathrm{C}$ a $30{ }^{\circ} \mathrm{C}$.

Rego et al. (2009) analisaram a germinação de sementes de B. salicifolius e $M$. gertii, espécies de Myrtaceae que frequentemente ocorrem em condições ecológicas semelhantes às de $M$. euosma. Foram constatados valores elevados de germinação em $B$. salicifolius em temperaturas de $20^{\circ} \mathrm{C}$ a $30^{\circ} \mathrm{C}(>75 \%)$ e intermediários em $35^{\circ} \mathrm{C}(50 \%)$. O IVG para esta espécie ficou em torno de 1,6 e o TM em torno de 20 dias. M. gertii também apresentou valores altos de germinação de $20^{\circ} \mathrm{C}$ a $25^{\circ} \mathrm{C}(90 \%)$, porém valores baixos acima de $30{ }^{\circ} \mathrm{C}\left(5 \%-35^{\circ} \mathrm{C}\right)$, com valores de IVG $=1,5\left(30^{\circ} \mathrm{C}\right), \mathrm{IVG}=7\left(20^{\circ} \mathrm{C}\right.$ e $\left.25^{\circ} \mathrm{C}\right)$ e $\mathrm{TM}$ entre $4,5\left(20^{\circ} \mathrm{C}\right.$ e $\left.25^{\circ} \mathrm{C}\right)$ e $7,2\left(30^{\circ} \mathrm{C}\right)$.

As altas taxas de germinação tanto na luz quanto no escuro podem contribuir para explicar a ocorrência da espécie tanto em ambientes com bastante luz disponível, como nas orlas das florestas (LEGRAND; KLEIN, 1970), quanto no sub-bosque das formações florestais, onde frequentemente ocorre (CARMO; MORELLATO, 2000). A independência de luz para germinação foi constatada por Rego (2010), para M. gertii, e por Santos et al. (2004), para C. xanthocarpa, enquanto que algumas outras espécies de Myrtaceae analisadas (A. sellowiana, M. pungens e $P$. cattleyanum) parecem ter fotoblastia positiva, com menores percentuais de germinação no escuro.

Considerando em conjunto as características morfológicas e os padrões de germinação da espécie, notase que esta possui características bastante favoráveis à sua propagação e possivelmente ao seu estabelecimento, uma vez que não depende de luz para a germinação e o faz em porcentagem elevada, originando plântulas capazes de se desenvolver rapidamente, sem depender de reservas do embrião. Essas características são típicas de espécies de crescimento rápido, heliófilas (GOGOSZ et al., 2015) e contribuem para explicar a grande plasticidade ecológica da espécie durante as fases iniciais do desenvolvimento.

\section{CONCLUSÕES}

- Myrceugenia euosma tem fruto do tipo baga, sementes com pequena quantidade de endosperma mucilaginoso e embrião do tipo mircióide. A plântula é epígea, fanerocotiledonar com paracotilédones, com forma ovada e eofilos elípticos.

- Os valores altos de porcentagem de germinação e de índice de velocidade e baixos de tempo médio, especialmente entre as temperaturas de $20^{\circ} \mathrm{C}$ e $25^{\circ} \mathrm{C}$, indicam que se trata de uma espécie com poucas restrições em termos de reprodução, no que se refere ao processo germinativo.

- A ausência de diferenças nos índices de germinação entre os tratamentos com presença e ausência de luz sugere que a espécie tenha um comportamento indiferente a este fator, podendo ser considerada fotoblástica neutra.

- Para os testes de germinação, recomenda-se a utilização dos substratos papel, areia e rolo de papel nas temperaturas $20^{\circ} \mathrm{C}$ e $25^{\circ} \mathrm{C}$ e nos substratos papel e areia na temperatura $30^{\circ} \mathrm{C}$.

\section{REFERÊNCIAS}

BARBIERI, R. L.; HEIDEN, G. Árvores de São Mateus do Sul e regiões. Brasília, Embrapa Informação Tecnológica, 2009. 356 p.

BRASIL. Ministério da Agricultura, Pecuária e Abastecimento. Secretaria de Defesa Agropecuária. Regras para análise de sementes. Brasília, 2009. 399 p. 
CARMO, M. R. B.; MORELlATO, L. P. Fenologia de árvores e arbustos das matas ciliares da bacia do rio Tibagi, Estado do Paraná, Brasil. In: RODRIGUES, R. R.; LEITÃO FILHO H. F. In: Matas ciliares: conservação e recuperação. São Paulo: Editora da Universidade de São Paulo, 2000, p. 125-141.

GAUTREAU, P.; LEZAMA, F. Clasificación florística de los bosques y arbustales de las sierras del Uruguay. Ecología Austral, v.19, p. 81-92, 2009.

GOGOSZ, A. M.; BONA, C.; SANTOS, G. O.; BOTOSSO, P. C. Germination and initial growth of Campomanesia xanthocarpa O. Berg. (Myrtaceae), in petroleum-contaminated soil and bioremediated soil. Brazilian Journal Biology, v. 70, n. 4, p. 977-986, 2010.

GOGOSZ, A. M.; BOEGER, M. R. T.; COSMO, N. L.; NOGUEIRA, A. C. Morfologia de diásporos e plântulas de espécies arbóreas da floresta com araucária, no sul do Brasil. Floresta, Curitiba, v. 45, n. 4, p. 819-832, 2015.

GOMES, J. P.; OLIVEIRA, L. M.; FERREIRA, P. I.; BATISTA, F. Substratos e temperaturas para teste de germinação em sementes de Myrtaceae. Ciência Florestal, Santa Maria, v. 26, n. 4, p. 285-293, 2016.

GOMES, J. P.; OliVEIRA, L. M.; FRANÇA, C. S. S.; DACOREGIO, H. M.; BORTOLUZZI, R. L. C. Caracterização morfológica de plântulas durante a germinação de sementes de Psidium cattleianum e Acca sellowiana (Myrtaceae). Ciência Florestal, Santa Maria, v. 25, n. 4, p. 1035-1042, 2015.

GOMES, J. P.; DACOREGIO, H. M.; SILVA, K. M.; ROSA, L. H.; BORTOLUZZI, R. L. C.; Myrtaceae na Bacia do Rio Caveiras: Características Ecológicas e Usos Não Madeireiros. Floresta Ambiente, v. 24, p. 1-10, 2017.

GRESSlER, E.; PIZO, M. A.; MORELlATO, L. P. C. Polinização e dispersão de sementes em Myrtaceae do Brasil. Revista Brasileira de Botânica, São Paulo, vol. 29, n. 4, p. 509-530, 2006.

HICKEY, L. J. A revised classification of the architecture of dicotyledonous leaves. In: METCALF, C. R.; CHALK, L. Anatomy of the dicotyledons. Oxford: Oxford University Press, 1979, p. 24-39.

LANDRUM, L. R. A Monograph of the genus Myrceugenia (Myrtaceae). Flora Neotropica. New York: The New York Botanical Garden, n. 29, 1981, 137 p.

LEGRAND, C. D.; KLEIN, R. M. Flora Ilustrada Catarinense: Mirtáceas. Itajaí: Herbário Barbosa Rodrigues, $1970,453 \mathrm{p}$.

LIMBERGER, R. P.; SIMOES-PIRES, C. A.; SOBRAL M.; MENU, C.; BESSIERE, J. M.; HENRIQUES, A. T. Essential oils from some Myrceugenia species (Myrtaceae). Flavour and Fragrance Journal, v. 17, n. 5, p. 341-344, 2002.

MARCHIORI, J. N. C.; SOBRAL. M. Dendrologia das Angiospermas: Myrtales. Santa Maria: Ed. da UFSM, 1997, $304 \mathrm{p}$.

METCALFE, C. R.; CHALK, L. Anatomy of the Dicotyledons. v.1., Oxford, Clarendon Press, 1950.

REGO, S. S.; COSMO, N. L.; GOGOSZ, A. M.; KUNIYOSHI, Y. S.; NOGUEIRA, A. C. Caracterização morfológica e germinação de sementes de Curitiba prismatica (D. Legrand) Salywon \& Landrum. Revista Brasileira de Sementes, v. 33, n. 4, p. 616-625, 2011.

REGO, S. S.; NOGUEIRA, A. C.; KUNIYOSHI, Y. S.; SANTOS, A. F. Caracterização morfológica do fruto, da semente e do desenvolvimento da plântula de Blepharocalyx salicifolius (H. B. K.) Berg. e Myrceugenia gertii Landrum - Myrtaceae. Revista Brasileira de Sementes, v. 32, n. 3, p. 52-60, 2010.

REGO, S. S; NOGUEIRA, A. C.; KUNIYOSHI, Y. S.; SANTOS, A. F. Germinação de sementes de Blepharocalyx salicifolius (H.B.K.) Berg. em diferentes substratos e condições de temperaturas, luz e umidade. Revista Brasileira de Sementes, v. 31, n. 2, p. 212-220, 2009.

SANTOS, C. M. R. dos.; FERREIRA, A.G.; ÁQUILA, M.E.A. Características de frutos e germinação de sementes de seis espécies de Myrtaceae nativas do Rio Grande do Sul. Ciência Florestal, v. 14, n. 2, p. 13-20, 2004.

SILVA, A. C.; HIGUCHI, P.; SOBRAL, M. E. G.; NEGRINI, M.; JÚNIOR, F. B.; BENTO, M. A.; SILVA, A. L.; MARCON, A. K.; FERREIRA, T. S.; SALAMI, B.; ROSA, A. D. Organização da comunidade e estrutura filogenética do componente arbóreo de um fragmento de floresta nebular no Planalto Catarinense. Ciência Florestal, Santa Maria, v. 27, n. 1, p. 129-141, 2017. 
SINGH, I. P.; BHARATE, S. B.; BHUTANI, K. K. Anti-HIV natural products. Current Science, v. 89, n. 2, p. 269-290, 2005.

SOUZA, V. C.; LORENZI, H. Botânica Sistemática: Guia ilustrado para identificação das famílias de angiospermas da flora brasileira, baseado em APG II. Nova Odessa, SP: Instituto Plantarum, 2005, 639 p.

VALÉRIO, A. F.; WATZLAWICK, L. F.; BALBINOT, R. Análise florística e estrutural do componente arbóreo de um fragmento de Floresta Ombrófila Mista em Clevelândia, Sudoeste do Paraná. Revista Acadêmica: Ciências Agrárias e Ambientais, Curitiba, v. 6, n. 2, p. 239-248, 2008.

VOGEL, E. F. Seedlings of dicotyledons: structure, development, types: descriptions of 150 woody Malesian taxa. Wageningen: Centre for Publishing and Documentation, 1980, $471 \mathrm{p}$. 